\title{
Adaptive backstepping control for ship nonlinear active fin system based on disturbance observer and neural network
}

\author{
Nguyen Thai Duong, Nguyen Quang Duy
}

Navigation Department, Faculty of Navigation, Vietnam Maritime University, Haiphong, Vietnam

\begin{tabular}{|c|c|}
\hline Article Info & ABSTRACT \\
\hline Article history: & \multirow{6}{*}{$\begin{array}{l}\text { Adaptive backstepping control based on disturbance observer and neural } \\
\text { network for ship nonlinear active fin system is proposed. One disturbance } \\
\text { observer is given to observe the disturbances of the system, by this way, the } \\
\text { response time is shorten and the negative impact of disturbance and } \\
\text { uncertain elements of the system is reduced. In addition, radial basic } \\
\text { function neural network (RBFNN) is proposed to approach the unknown } \\
\text { elements in the ship nonlinear active fin system, therefor the system can } \\
\text { obtain good roll reduction effectiveness and overcome the uncertainties of } \\
\text { the model, the designed controller can maintain the ship roll angle at desired } \\
\text { value. Finally, the simulation results are given for a supply vessel to verify } \\
\text { the successfulness of the proposed controller. }\end{array}$} \\
\hline Received Feb 17, 2021 & \\
\hline Revised Sep 9, 2021 & \\
\hline Accepted Oct 6, 2021 & \\
\hline Keywords: & \\
\hline $\begin{array}{l}\text { Adaptive backstepping control } \\
\text { fin stabilizer } \\
\text { Disturbance observer }\end{array}$ & \\
\hline
\end{tabular}

This is an open access article under the CC BY-SA license.

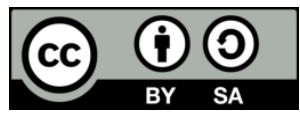

\section{Corresponding Author:}

Nguyen Thai Duong

Faculty of Navigation, Vietnam Maritime University

484 Lach Tray, Le Chan, Hai Phong, Vietnam

Email: nguyenthaiduong@vimaru.edu.vn

\section{INTRODUCTION}

Vessels are sailing in bad weather conditions, due to effect of the external disturbances such as wave, wind and current can produce large amplitude roll motion, this is a dangerous phenomenon, it affects to the comfortable of the crew, cargo and ship, this phenomenon also affects to the vessels economic efficiency, therefore, research to reduce roll motion is a very important task. To perform that issue, there are some devices which have been researched to reduce roll motion [1]-[4] and can be named as bilge keels, antirolling tanks. But, due to the limitation of those devices, the active fin stabilizer has been researched with high efficiency in the roll reduction. Due to the superior of roll reduction ability, active fin has been researched very early and became a hotspot in the ship control filed [5]. Numerous researches on ship roll reduction by using active fin have been researched since 1940s. For example, a robust fin roll reduction was use for surface ship, and achieved good roll reduction effectiveness [6]. An adaptive backstepping controller and sliding mode controller were propose for active fin with radial basic function (RBF) neural network. The effectiveness of this device is highly dependent on the controller, therefore, researching to design an active fin controller with high roll reduction efficiency is also a very important task.

Nowadays, control techniques have great progress, therefore there are many control methods have been researched for roll reduction control with fin stabilizer system. With advantages are reliability and simplicity, the proportional integral derivative (PID) control method was applied to reduce the roll motion in [7]. But, the disadvantage of the PID method is reduced adaptability and robustness of the system. Otherwise, design a controller within a linear model will be difficult to achieve high effectiveness of roll reduction due to roll motion is caused by the nonlinear dynamics when the ships are sailing in rough sea condition. To solve parameters variable and nonlinear dynamics problems, there are many robust algorithms, such as model 
predictive control [8], [9], sliding-mode control [10], [11], fuzzy control [12], [13], were proposed for fin stabilizer system. However, with the ship model parameters uncertainty problem, adaptive backstepping control is considered as good solution for active fin system. As we all know, uncertainty parameters are caused by the system perturbation are compensated by using adaptive control technique, the update laws were used to replace the unknown parameters, and the nonlinear system mismatch problem is solved by using backstepping method. The virtual control input was chosen as the appropriate state variable, control variable output of each backstepping process was produced according to the previous process, and when ended the repeat process, the actual controller was obtained by optimal the Lyapunov function.

In recent years, how to improve roll reduction efficiency received significant attention in the ship control field. To improve roll reduction efficiency, the main task is to overcome problems which generated by disturbances. With fin stabilizer system, the uncertainties mainly generated by the unknown disturbances which was not repeated or modeled. To reduce above mention uncertainties, there are some control methods which have been studied for ship active fin system such as, robust control, Ho control [14], neural networks (NNs) control [15]. However, in the modern manufacture, the faster and accurate response is requested even under larger disturbances. To solve this problem, disturbance observer (DOB) was applied in [16], [17]. The approximate disturbance is estimated by comparing the real system's control input and the symbolic model is main idea of the DOB. Through the symbolic model output response, the control input signal of virtual system is defined. The symbolic system is made by estimated disturbances, which is the feedback signal as a cancellation signal. DOB has some advantages can be named as robustness, less computational burden and high performance. For example in [18], based on DOB, a robust leader follower synchronization was proposed for under-actuated vessels. The DOB is effectively applied to the ship surge and yaw motions in this study and achieved good disturbance estimation. In our work, the DOB will be applied to the roll motion of the ship. In [19], an adaptive synchronization was proposed for marine surface vessels based on DOB, in this research, the leader-follower ship synchronization anti disturbance capability was improved by using DOB. Studies have also shown that disturbance observer also achieves good results with fast time varying disturbances, although it is designed for slow variable disturbances.

As we all known, NNs is widely researched and achieved good results in ship control field. in [20], the functions parametric perturbation of the fin stabilizer system were tracked by used the NNs and achieved unexpected results. Ghassemi et al. [21] showed the controller which was combined between PID control and neural network for roll reduction control with low draught ship. In [22], an adaptive backstepping with RBF neural network was given for active fin without accurate model, the roll reduction effectiveness and the system robustness were obtained with the designed control strategy, however, the controller singularity can cause a potential risk. In our work, by combining the adaptive backstepping method with NNs and DOB, the proposed method can overcome the problems of controller singularity and mismatch, the perturbation parameters of the active fin system were also overcome by used the mentioned above methods.

An adaptive controller for ship nonlinear active fin system with disturbances is presented in this paper. The proposed controller is combination the adaptive backstepping method with the radial basic function NN and the disturbance observer technique. The given scheme guarantees the stability of all closedloop signals. With proposed controller, the system parameters uncertainty can be solved, the system disturbances can be estimated, and this method overcomes the mismatch problems, the response time is greatly reduced, and will achieve better roll reduction robustness and effectiveness.

The paper's rest are arranged as: the ship nonlinear active fin stabilizer system, wave disturbance model and disturbance observer will be presented in section 2. Controller design is proposed in section 3. Section 4 is simulation results. Finally, section 5 is this paper concludes.

\section{PRELIMINARIES}

When sailing in rough sea conditions, the ship stability is affected by roll motion, determine exact dynamics forces that affect to the vessel motions is very difficult, in this paper, we study the stability of the vessel in relative to roll motion. So, the ship nonlinear active fin model is given as [23], [24].

$$
\left(M_{x}+\Delta M_{x}\right) \ddot{\varphi}+\xi_{n} \dot{\varphi}+\xi_{w} \dot{\varphi}|\dot{\varphi}|+D_{p} h_{m} \varphi\left[1-\left(\varphi / \varphi_{f l}\right)^{2}\right]=H_{c t}+H_{w t}
$$

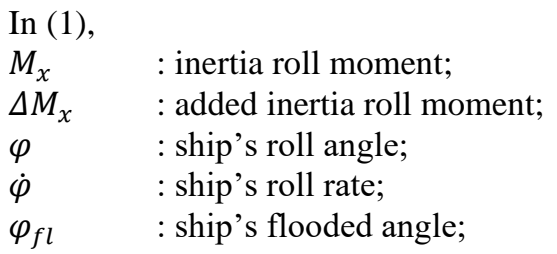


$H_{c t} \quad$ : fin's control moment;

$H_{w t} \quad$ : sea wave's acting moment;

$D_{p} \quad$ : displacement of the ship;

$h_{m} \quad$ : ship's initial metacentric height;

$\xi_{n}$ and $\xi_{w}$ : damping coefficients.

$M_{x}, \Delta M_{x}, \xi_{n}, \xi_{w}, H_{c t}$ can be given as:

$$
\begin{aligned}
& M_{x}+\Delta M_{x}=\frac{D_{p} B_{r e}^{2}}{g}\left(0.3085+\frac{0.0227 B_{r e}}{d_{r f}}-\frac{0.0043 L_{P}}{100}\right)^{2} \\
& \xi_{n}=\frac{2 r_{1} \sqrt{D_{p} h_{m}\left(M_{x}+\Delta M_{x}\right)}}{\pi} \xi_{w}=\frac{3 r_{2}\left(M_{x}+\Delta M_{x}\right)}{4} \\
& H_{c t}=-\rho v^{2} S_{f} l_{f} C_{l f}\left(\alpha_{f}+\frac{\dot{\varphi} l_{f}}{v}\right)
\end{aligned}
$$

where $B_{r e}$ is the ship's breadth, $L_{P}$ is the ship's length, $d_{r f}$ is the vessel draft, $r_{1}, r_{2}$ are test factors, $\rho$ is seawater density, $v$ is the vessel speed, $S_{f}$ is fin area, $l_{f}$ is the fin's acting force arm, $C_{l f}$ is the lift coefficient of fin, and $\alpha_{f}$ is the rotation angle of fin. Take $\Delta M_{x}, M_{x}, \xi_{w}, \xi_{n}$ and $H_{c t}$ instead of (1), we can get:

$$
\ddot{\varphi}=\gamma_{1} \varphi+\gamma_{2} \varphi^{3}+\gamma_{3} \dot{\varphi}+\gamma_{4} \dot{\varphi}|\dot{\varphi}|+\sigma \alpha_{f}+d
$$

where $\gamma_{1}, \gamma_{2}, \gamma_{3}, \gamma_{4}, \sigma$ are coefficients, $d$ is sea wave disturbance.

Denoted the state variables $x=\left[x_{1}, x_{2}\right]^{T}=[\varphi, \dot{\varphi}]^{T}$, the output signal $y=\varphi=x_{1}$, and $u=\alpha_{f}$ is the input signal. From (5) can be written as:

$$
\left\{\begin{array}{l}
\dot{x}_{1}=x_{2} \\
\dot{x}_{2}=f(\bar{x})+g(\bar{x}) u+d \\
y=x_{1}
\end{array}\right.
$$

Assumption 1. $g$ is an unknown smooth function, and signs of $g$ is known. And exist constant $g_{1}>g_{2}>0$ satisfy $g_{1}>|g|>g_{2}$, and Exist constant $g_{d}>0$ such that $\left|\dot{g}_{i}\right| \leq g_{i d}$.

Lemma 1. If $V(t, x)$ is positive definite, and $\dot{V} \leq-k_{1} V+k_{2}$, with $k_{1} \geq 0, k_{2} \geq 0$ are bounded, and then $V(t, x) \leq k_{2} / k_{1}+\left(V(0)-k_{2} / k_{1}\right) e^{-k_{1} t}$

\subsection{Disturbance observer}

The second function in (6) is rewritten as:

$$
d=\dot{x}_{2}-f(\bar{x})-g(\bar{x}) u
$$

The disturbance observer is proposed as:

$$
\dot{\hat{d}}=-K\left(x_{1}, x_{2}\right) \hat{d}+K\left(x_{1}, x_{2}\right)\left(\dot{x}_{2}-f(\bar{x})-g(\bar{x}) u\right)
$$

where $K\left(x_{1}, x_{2}\right)=a$ is the parameter with $a>0$ is designed. Due to the disturbance's derivative there is no prior information, so assuming that disturbance in (6) varies slowly [25].

$$
\dot{d}=0
$$

We defined observer error as difference between estimated and actual disturbance

$$
\tilde{d}=d-\hat{d}
$$

which can be written as in (11).

$$
\dot{\tilde{d}}=-K\left(x_{1}, x_{2}\right) \tilde{d}
$$


We can see that, in (6), $\dot{x}_{2}$ is hard to obtain, this signal is essential to realize the disturbance observer. To solve this problem, an auxiliary variable is defined as:

$$
\begin{aligned}
& r=\hat{d}-q\left(x_{2}\right) . \text { Defining } \\
& \dot{q}\left(x_{2}\right)=K\left(x_{1}, x_{2}\right) \dot{x}_{2}
\end{aligned}
$$

then

$$
\dot{r}=-K\left(x_{1}, x_{2}\right) r+K\left(x_{1}, x_{2}\right)\left(-f(\bar{x})-g(\bar{x}) u-q\left(x_{2}\right)\right)
$$

The estimated disturbance is obtained by:

$$
\hat{d}=r+q\left(x_{2}\right)
$$

and it is known that

$$
\hat{d}=r+q\left(x_{2}\right)
$$

We design

$$
u_{d}=\hat{d} / g(\bar{x})
$$

The second function in (6) is rewritten as:

$$
\dot{x}_{2}=f(\bar{x})+g(\bar{x})\left(v-u_{d}\right)+d=f(\bar{x})+g(\bar{x}) v+\tilde{d}
$$

where $\tilde{d}=d-\hat{d}, u=v-u_{d}$ and the system (6) is transformed as:

$$
\left\{\begin{array}{l}
\dot{x}_{1}=x_{2} \\
\dot{x}_{2}=f(\bar{x})+g(\bar{x}) v+\tilde{d} \\
y=x_{1}
\end{array}\right.
$$

The disturbance observer's structure is shown in Figure 1. In the next section, a new design procedure is developed for the system (18) by using the adaptive backstepping method and radial basis function NN.

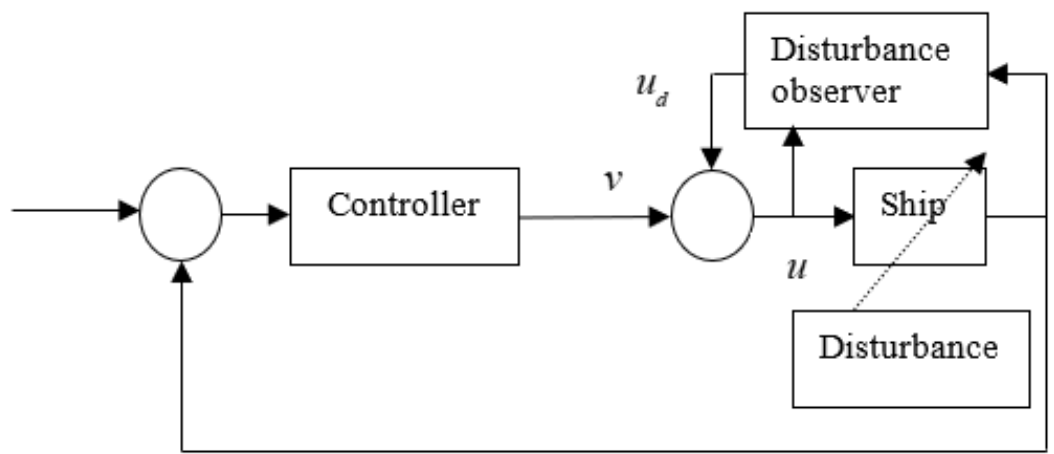

Figure 1. Disturbance observer's structure

\section{CONTROL SYSTEM DESIGN}

\subsection{RBF neural network}

In nearly years, radial basic function neural network (RBFNN) have been widely studied, please refer [26] for detailed treatment of RBFNN. In this paper, RBFNN model is given as:

$$
h_{m m}(z)=W^{T} F(z)
$$


In (19), input vector $z \in \Omega \in R^{m}, W=\left[w_{1}, w_{2}, \ldots, w_{n}\right]$ is weight vector, $n$ is node number of the NN, and $F(z)=\left[f_{1}(z), f_{2}(z), \ldots, f_{n}(z)\right]$ with $f_{i}(z)$ is chosen as Gaussian functions

$$
f_{i}(z)=\exp \left[\frac{-\left(z-\gamma_{i}\right)^{T}\left(z-\gamma_{i}\right)}{\varepsilon_{i}^{2}}\right]
$$

where $i=1,2, \ldots, n, \gamma_{i}=\left[\gamma_{i 1}, \gamma_{i_{2}}, \ldots, \gamma_{i_{m}}\right]^{T}$ is the receptive field center, $\varepsilon_{i}$ is the Gaussian function's width.

As we all known that, using RBFNN to approximate an unknown continuous function $f(x)$ over compact sets, we can obtain

$$
f(x)=W^{* T} F(x)+\eta \quad \forall x \in \Omega \subseteq R^{m}
$$

In (21) the approximation error is $\eta$, the basic function $F(x)$, and $w^{*}$ is ideal weight matrix. The ideal matrix $w^{*}$ is an "artificial" quantity which is given for analytical purpose and have form as:

$$
w^{*}=\arg \min _{w \in R^{m}}\left\{\sup _{x \in \Omega}\left|f(x)-W^{T} F(x)\right|\right\}
$$

\subsection{Control design}

Step 1: The variable error is defined $z_{1}=x_{1}$, the virtual control law is choosen as $\alpha_{2}$. The second variable error is defined

$$
z_{2}=x_{2}-\alpha_{2}
$$

The $z_{1}$ first derivative is calculated as:

$$
\dot{z}_{1}=z_{2}+\alpha_{2}
$$

Virtual control law is defined as:

$$
\alpha_{2}=-c_{1} z_{1}
$$

The Lyapunov function is considered $V_{1}=z_{1}^{2} / 2$ and the first derivative of $V_{1}$ as:

$$
\dot{V}_{1}=-c_{1} z_{1}^{2}+z_{1} z_{2}
$$

Step 2: We define $z_{2}=x_{2}-\alpha_{2}$ and the differentiate $z_{2}$ with time yield's respect is

$$
\dot{z}_{2}=f(\bar{x})+g(\bar{x}) v+\tilde{d}-\dot{\alpha}_{2}
$$

with $f(\bar{x})$ and $g(\bar{x})$ are unknown, $\dot{\alpha}_{2}$ is unknown scalar function. We define $h(\bar{x})$ and using a radial basis function neural network $\psi^{* T} \rho(\bar{x})$ to approximate $h(\bar{x})$ as:

$$
h(\bar{x})=\frac{1}{g(\bar{x})}\left(f(\bar{x})+\tilde{d}-\dot{\alpha}_{2}\right)=\psi^{* T} \rho(\bar{x})+\varsigma^{*}
$$

In $(28) \psi^{*}$ is the ideal weights, and the approximate error $\varsigma^{*}>0$ is a constant, then (27) can be writen as:

$$
\dot{z}_{2}=g(\bar{x})\left(v+\psi^{* T} \rho(\bar{x})+\varsigma^{*}\right)
$$

The control law is chosen as:

$$
v=-c_{2} z_{2}-\widehat{\psi}^{T} \rho(\bar{x})
$$

In (30) $\hat{\psi}$ is the estimate parameter of $\psi^{*}$ matrix, denote $\tilde{\psi}=\hat{\psi}-\psi^{*}$ is the parameter error, we have:

$$
\dot{z}_{2}=g(\bar{x})\left(-c_{2} z_{2}-\tilde{\psi}^{T} \rho(\bar{x})+\varsigma^{*}\right)
$$


We consider the Lyapunov function as:

$$
V_{2}=V_{1}+\frac{1}{2} \frac{z_{2}^{2}}{g(\bar{x})}+\frac{1}{2} \tilde{\psi}^{T} T^{-1} \tilde{\psi}
$$

with $T=T^{T}>0$ is the adaptation gain vector, the first derivetive of $V_{2}$ is

$$
\dot{V}_{2}=\dot{V}_{1}-c_{2} z_{2}^{2}+z_{2} \varsigma^{*}+\tilde{\psi} T^{-1}\left(\dot{\hat{\psi}}-T \rho z_{2}\right)+\frac{z_{2}^{2} \dot{g}(\bar{x})}{2(g(\bar{x}))^{2}}
$$

The adaptation law is considered as in (34):

$$
\dot{\hat{\psi}}=T\left(\rho z_{2}-\delta \hat{\psi}\right)
$$

with $\delta>0$ is a constant. By using (26), (31), and (34), we obtain the first derivative of $V_{2}$ as in (35).

$$
\dot{V}_{2}=c_{1} z_{1}^{2}-c_{2} z_{2}^{2}+z_{1} z_{2}+z_{2} \varsigma^{*}-\delta \tilde{\psi}^{T} \hat{\psi}+\frac{z_{2}^{2} \dot{g}(\bar{x})}{2(g(\bar{x}))^{2}}
$$

Refer to the facts

$$
z_{1} z_{2} \leq z_{1}^{2}+\frac{1}{4} z_{2}^{2} ; \quad z_{2} \varsigma^{*} \leq z_{2}^{2} \frac{1}{4} \varsigma^{*^{2}}
$$

then

$$
\begin{aligned}
& \dot{V}_{2} \leq-\left(c_{1}-1\right) z_{1}^{2}-\left(c_{2}-\frac{5}{4}\right) z_{2}^{2}+\frac{1}{4} \varsigma^{*^{2}} \\
& -\frac{\delta}{2}\left(\left\|\tilde{\psi}_{i}\right\|^{2}-\left\|\psi_{i}^{*}\right\|^{2}\right)+\frac{z_{2}^{2} \dot{g}(\bar{x})}{2(g(\bar{x}))^{2}}
\end{aligned}
$$

Note that,

$$
-\left(c_{2} z_{2}^{2}+\frac{z_{2}^{2} \dot{g}(\bar{x})}{2(g(\bar{x}))^{2}}\right) \leq-\left(c_{2} z_{2}^{2}+\frac{z_{2}^{2} \dot{g}_{d}(\bar{x})}{2(g(\bar{x}))^{2}}\right)
$$

$c_{2}$ is choosen such that

$$
c_{2}^{*}=\frac{\left(c_{2}-g(\bar{x})\right)}{2 g_{0}^{2}(\bar{x})}>0
$$

Denote that

$$
c_{1}-1=c_{11} ; c_{2}-\frac{5}{4}=c_{22} ; \frac{1}{4} \varsigma^{*^{2}}+\frac{\delta}{2}\left\|\psi_{i}^{*}\right\|^{2}=k
$$

We pay attention to $\left|\varsigma^{*}\right| \leq \varsigma_{N}$ and $\left\|\psi^{*}\right\| \leq \psi_{N}$. Then can get:

$$
k_{i} \leq \frac{1}{4} \varsigma_{N}^{2}+\frac{\delta_{i}}{2} \psi_{N}^{2}=k_{N}=L
$$

then

$$
\dot{V}_{2} \leq-c_{11} z_{1}^{2}-c_{22} z_{2}^{2}-\frac{\delta}{2 \lambda \widetilde{\overline{1}_{\max }} T^{-1}}
$$

Let

$$
c_{11}=\frac{C}{2} ; c_{22}=\frac{C}{2 g(\bar{x})} ; \frac{\delta}{2 \lambda-1 \max \frac{C}{2}}
$$


with $C>0$ is bound constant and satisfies $\delta \geq C \lambda-1_{\max }$ and it follows

$$
\dot{V}_{2} \leq-C V_{2}+L
$$

with the assumptions and lemma 1 which are given in section 2, (44) shows that $\dot{V}_{2}$ is bounded. That means the bounded stability of system (6) is guaranteed.

\section{SIMULATION RESEARCH}

The design vessel is used for simulation, which have the parameters as given in Table 1 . In the simulation, the parameters were selected as: $\gamma_{1}=-0.2117, \gamma_{2}=0.2939, \gamma_{3}=0.6748, \gamma_{4}=-0.113$, $\delta=0.01, T=\operatorname{diag}\{0.001\}, c_{1}=0.1, c_{2}=2$, fin angle $|\alpha| \leq 25 \mathrm{deg} . n=135$ is node number of the NN, $\varepsilon_{i}=2(i=1 \ldots 25)$. External disturbance is given as square-wave and sinusoidal signal. The control performance is illustrated in below simulation results. The disturbance is choice as sinusoidal signal $d=$ $0.25 \sin (0.8 t)$ and square-wave signal: $d=0.25(\operatorname{sign}(\sin (0.8 t)))$.

Table 1. Vessel parameters

\begin{tabular}{cc}
\hline \multicolumn{2}{c}{ Vessel parameters } \\
\hline Ship's length & $175 \mathrm{~m}$ \\
Ship's breadth & $25 \mathrm{~m}$ \\
Draft & $8.0 \mathrm{~m}$ \\
Displacement & $21130 \mathrm{t}$ \\
Fin area & $20 \mathrm{~m}^{2}$ \\
The fin acting force arm & $15.0 \mathrm{~m}$ \\
Fin fift coefficient & 3.4 \\
Ship's flooding angle & $45\left(^{\circ}\right)$ \\
Shp's Initial metacentric height & $5.5 \mathrm{~m}$ \\
Ship's speed & $18 \mathrm{kts}$ \\
\hline
\end{tabular}

As we shown in Figure 2 and Figure 3 the roll angle is reduced to the desire value and this value is maintained that mean the effectiveness of the proposed controller is illustrated. Figure 4 and Figure 5 shown that the system's disturbance is estimated very well with proposed disturbance observer. Figure 6 and Figure 7 shown that the controller designed has the response time close to $2 \mathrm{~s}$ while response time of the controller without disturbance observer close to $10 \mathrm{~s}$ which is shown in Figure 8 and close to $20 \mathrm{~s}$ which is shown in Figure 9, that mean, by using disturbance observer, the response time is greatly reduced.

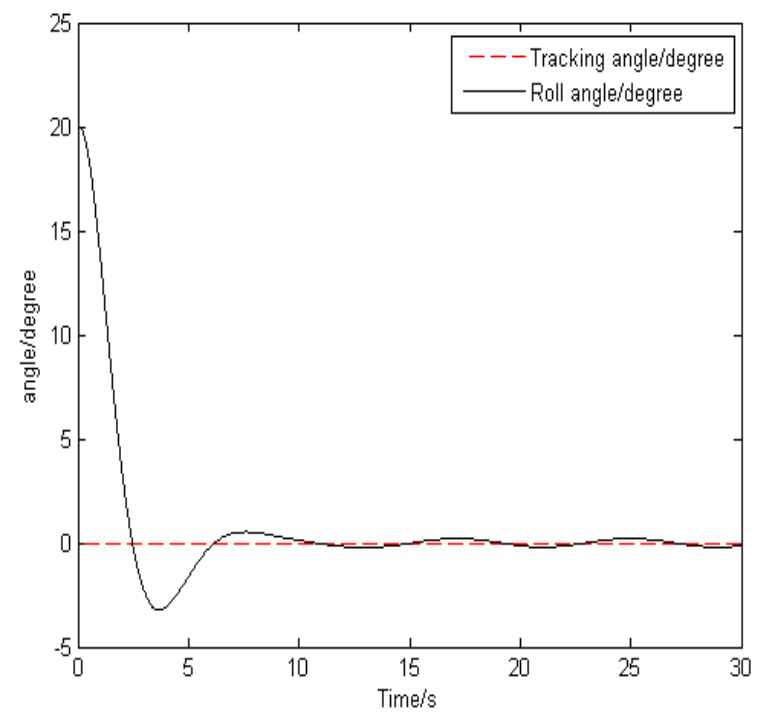

Figure 2. The ship roll angle with $d=0.25 \sin (0.8 t)$

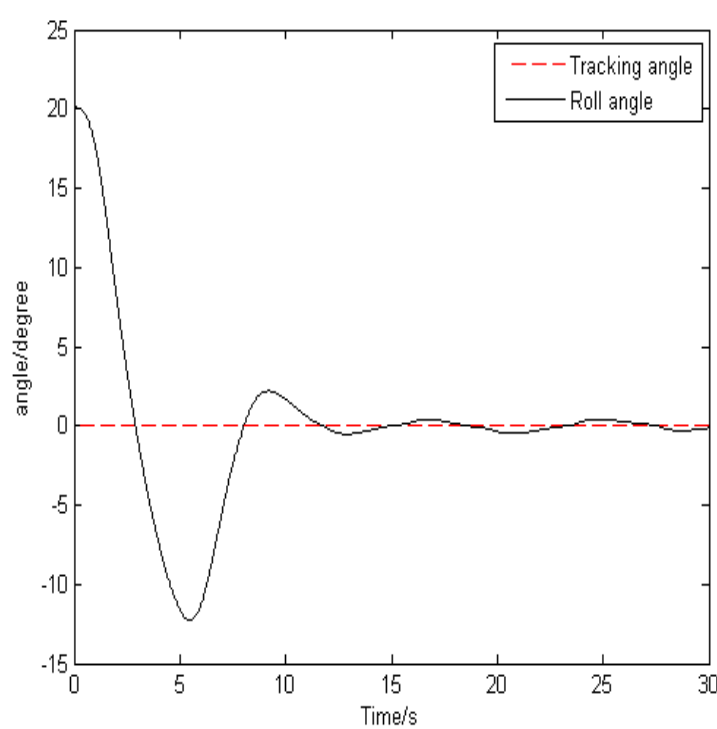

Figure 3. The ship roll angle with $d=0.25(\operatorname{sign}(\sin (0.8 t)))$ 


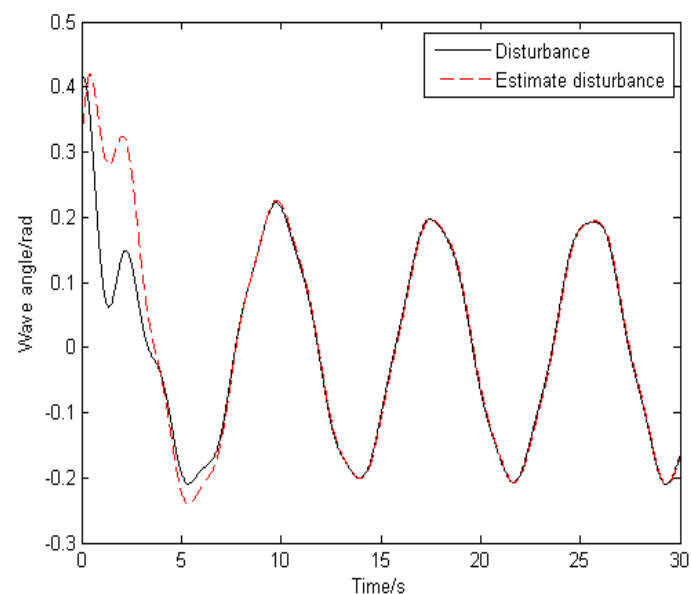

Figure 4. Disturbance observer with $d=0.25 \sin (0.8 t)$

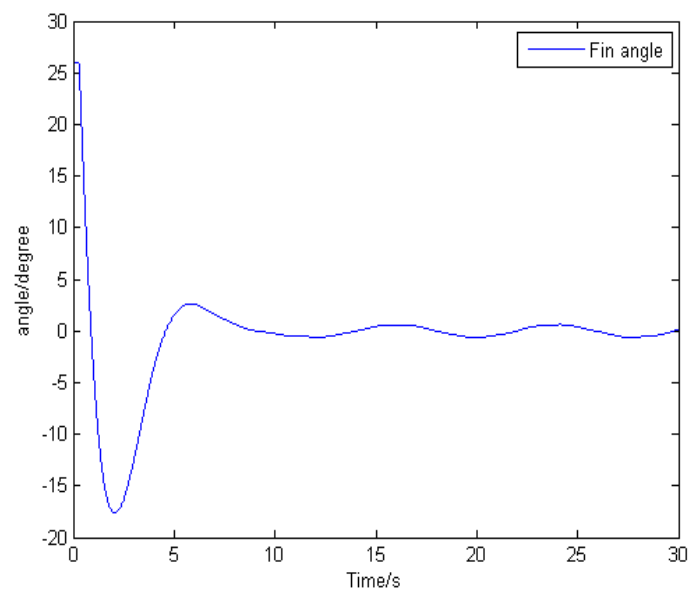

Figure 6. The fin angle with $d=0.25 \sin (0.8 t)$

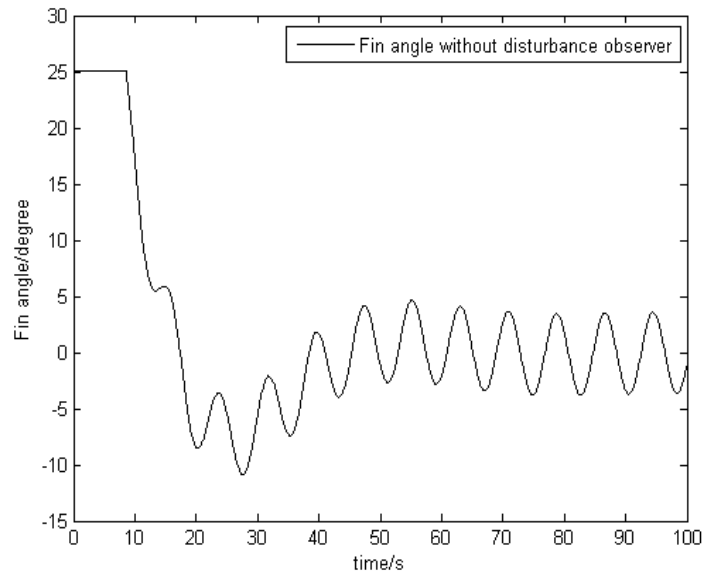

Figure 8 . The fin angle without disturbance observer with $d=0.25 \sin (0.8 t)$

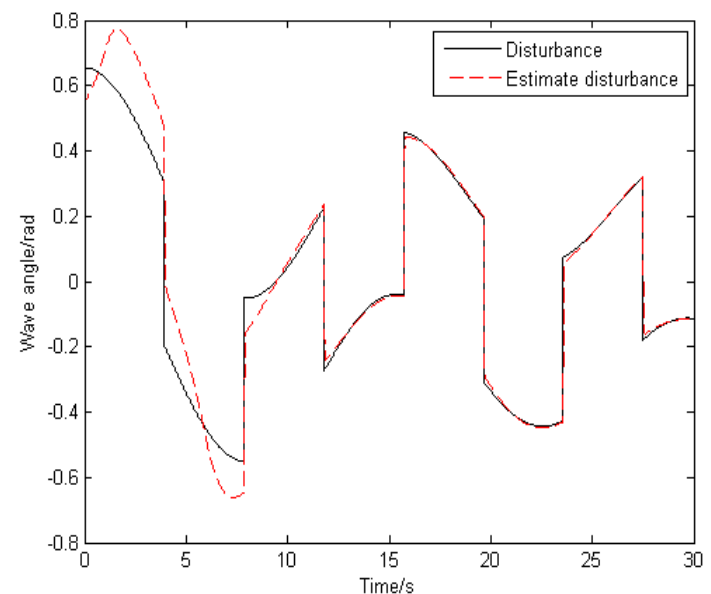

Figure 5. Disturbance observer with $d=0.25(\operatorname{sign}(\sin (0.8 t)))$

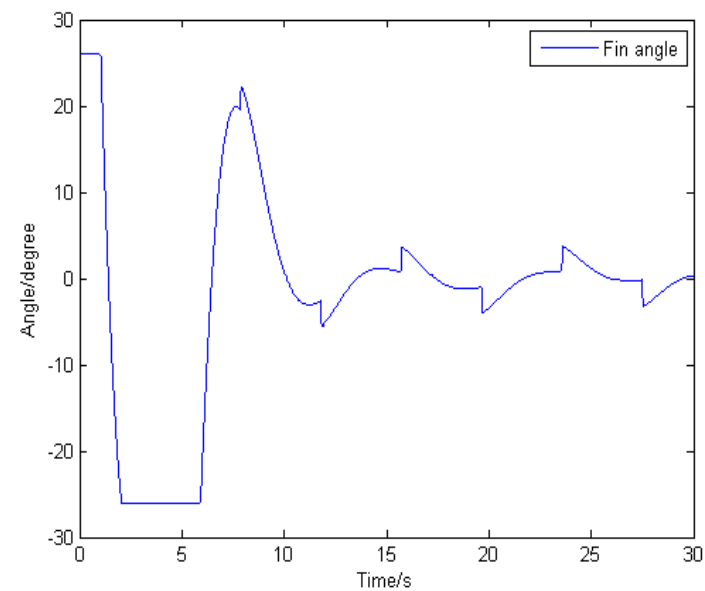

Figure 7 . The fin angle with $d=0.25(\operatorname{sign}(\sin (0.8 t)))$

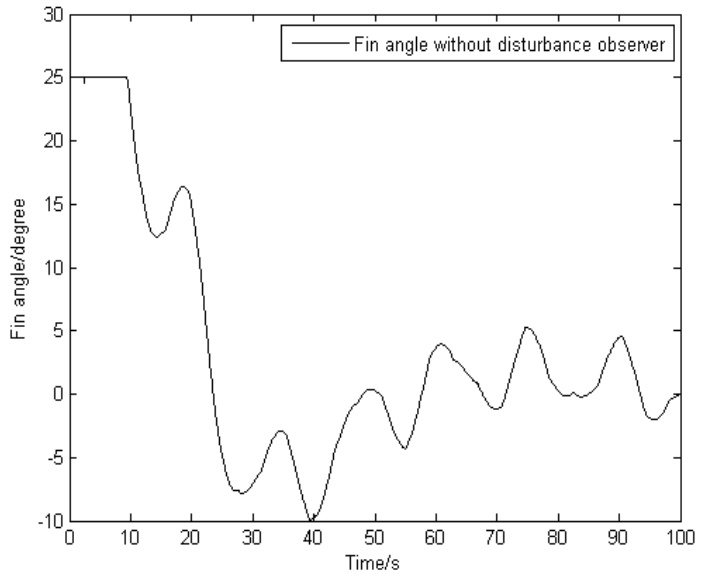

Figure 9. The fin angle without disturbance observer with $d=0.25(\operatorname{sign}(\sin (0.8 t)))$ 


\section{CONCLUSION}

In our work, an adaptive control scheme based on NN and disturbance observer for ship nonlinear active fin system is proposed. One disturbance observer is given to estimate the system's disturbances, in addition, RBFNN is proposed to approach the unknown elements in the ship nonlinear active fin system, and therefore the system can obtain good roll reduction effectiveness and overcome the uncertainties of the model. Unknown disturbance and system parameters were solved with the proposed method. The simulation results illustrate that good roll reduction efficiency can be achieved.

\section{REFERENCES}

[1] M. Gachet and J. G. Kherian, "Impact of linearization of bilge keel damping on the early assessment of vessel operability," in Proceedings of the International Conference on Offshore Mechanics and Arctic Engineering - OMAE, Jan. 2008, vol. 1, pp. 257264, doi: 10.1115/OMAE2008-57255.

[2] T. Perez and M. Blanke, "Ship roll damping control," Annual Reviews in Control, vol. 36, no. 1, pp. 129-147, Apr. 2012, doi: 10.1016/j.arcontrol.2012.03.010.

[3] M. Wang, Y. Yu, and B. Zeng, "Neuro-fuzzy controller for rudder roll stabilization of ships," Applied Mechanics and Materials, vol. 66-68, pp. 1278-1285, Jul. 2011, doi: 10.4028/www.scientific.net/AMM.66-68.1278.

[4] J. F. O’Brien, "Multi-path nonlinear dynamic compensation for rudder roll stabilization," Control Engineering Practice, vol. 17, no. 12, pp. 1405-1414, Dec. 2009, doi: 10.1016/j.conengprac.2009.06.008.

[5] S. Sun, J. Hu, J. Yin, and T. Jiang, "Design of simplified fuzzy controller for ship fin stabilizer," in Proceedings of the 33rd Chinese Control Conference, CCC 2014, Jul. 2014, pp. 4534-4538, doi: 10.1109/ChiCC.2014.6895702.

[6] N. A. Hickey, M. J. Grimble, M. A. Johnson, M. R. Katebi, and R. Melville, "Robust fin roll stabilization of surface ships," in Proceedings of the IEEE Conference on Decision and Control, 1997, vol. 5, pp. 4225-4230, doi: 10.1109/cdc.1997.649497.

[7] S. Surendran, S. K. Lee, and S. Y. Kim, "Studies on an algorithm to control the roll motion using active fins," Ocean Engineering, vol. 34, no. 3-4, pp. 542-551, Mar. 2007, doi: 10.1016/j.oceaneng.2006.01.008.

[8] L. Liang and Y. Wen, "Integrated rudder/fin control with disturbance compensation distributed model predictive control," IEEE Access, vol. 6, pp. 72925-72938, 2018, doi: 10.1109/ACCESS.2018.2881752.

[9] T. Perez and G. C. Goodwin, "Constrained predictive control of ship fin stabilizers to prevent dynamic stall," Control Engineering Practice, vol. 16, no. 4, pp. 482-494, Apr. 2008, doi: 10.1016/j.conengprac.2006.02.016.

[10] L. Liang, M. Sun, and T. Luan, "Design sliding mode control of fuzzy switching gain for lift-feedback fin stabilizers," in 2016 IEEE International Conference on Mechatronics and Automation, IEEE ICMA 2016, Aug. 2016, pp. 1412-1417, doi: 10.1109/ICMA.2016.7558770.

[11] M. Moradi and H. Malekizade, "Robust adaptive first-second-order sliding mode control to stabilize the uncertain fin-roll dynamic," Ocean Engineering, vol. 69, pp. 18-23, Sep. 2013, doi: 10.1016/j.oceaneng.2013.05.003.

[12] F. Alarçin, "Nonlinear modelling of a fishing boat and fuzzy logic control design for electro-hydraulic fin stabilizer system," Nonlinear Dynamics, vol. 76, no. 1, pp. 581-590, Apr. 2014, doi: 10.1007/s11071-013-1152-9.

[13] S. Surendran and V. Kiran, "Control of ship roll motion by active fins using fuzzy logic," Ships and Offshore Structures, vol. 2, no. 1, pp. 11-20, Jan. 2007, doi: 10.1533/saos.2006.0105.

[14] X. Han, W. Deng, Q. Sun, and Y. Zhao, "Direct adaptive fuzzy Hळ tracking control for a class of uncertain nonlinear systems based on LMI technique," in 2010 Chinese Control and Decision Conference, May 2010, pp. 3019-3023, doi: 10.1109/CCDC.2010.5498657.

[15] W. Bai, T. Li, X. Gao, and K. T. Myint, "Neural network based direct adaptive backstepping method for fin stabilizer system," Lecture Notes in Computer Science (including subseries Lecture Notes in Artificial Intelligence and Lecture Notes in Bioinformatics), vol. 7952, no. 2, pp. 212-219, 2013, doi: 10.1007/978-3-642-39068-5_26.

[16] C. Zang, J. Juntawongso, K. Hashikura, M. A. S. Kamal, and K. Yamada, "Disturbance observers for general exogenous disturbances," in 2019 IEEE International Conference on Mechatronics and Automation (ICMA), Aug. 2019, pp. 1986-1991, doi: 10.1109/ICMA.2019.8816576.

[17] S. Sun and X. Wei, "Fault-tolerant control based on disturbance observer for stochastic systems," in Chinese Control Conference, CCC, Jul. 2017, pp. 1913-1918, doi: 10.23919/ChiCC.2017.8027633.

[18] X. Hu, X. Wei, Y. Kao, and J. Han, "Robust synchronization for under-actuated vessels based on disturbance observer," IEEE Transactions on Intelligent Transportation Systems, pp. 1-10, 2021, doi: 10.1109/TITS.2021.3054177.

[19] X. Hu, X. Wei, Q. Gong, and J. Gu, "Adaptive synchronization of marine surface ships using disturbance rejection without leader velocity,” ISA Transactions, vol. 114, pp. 72-81, Aug. 2021, doi: 10.1016/j.isatra.2020.12.044.

[20] K. Tian-zeng, L.De-hong, Y. Feng-xiang, and N. Yuan-zen, "The study of neural network control system of the fin stabilizer," Ship Engineering, vol. 34, no. 2, pp. 278-301, 2012.

[21] H. Ghassemi, F. Dadmarzi, P. Ghadimi, and B. Ommani, "Neural network-PID controller for roll fin stabilizer," Polish Maritime Research, vol. 17, no. 2, pp. 23-28, Jan. 2010, doi: 10.2478/v10012-010-0014-3.

[22] Y. Zhang, W. Shi, L. Yin, M. Qiu, and L. Zhao, "Adaptive backstepping and sliding mode control of fin stabilizer based on RBF neural network," in 2009 IEEE International Conference on Intelligent Computing and Intelligent Systems, Nov. 2009, pp. 302307, doi: 10.1109/ICICISYS.2009.5358062.

[23] M. Ertogan, S. Ertugrul, and M. Taylan, "Application of particle swarm optimized PDD2 control for ship roll motion with active fins," IEEE/ASME Transactions on Mechatronics, vol. 21, no. 2, pp. 1004-1014, Apr. 2016, doi: 10.1109/TMECH.2015.2479401.

[24] Q. Nguyen, T. Li, J. Ning, and Y. Wu, "Online optimal control for nonlinear fin stabilizer system of marine vessels via time-based ADP algorithm," in 2020 15th IEEE Conference on Industrial Electronics and Applications (ICIEA), Nov. 2020, pp. 264-271, doi: 10.1109/ICIEA48937.2020.9248167.

[25] T. Mita, M. Hirata, K. Murata, and H. Zhang, "H/sub $\infty /$ control versus disturbance-observer-based control," IEEE Transactions on Industrial Electronics, vol. 45, no. 3, pp. 488-495, Jun. 1998, doi: 10.1109/41.679007.

[26] S. S. Ge, C. C. Hang, T. H. Lee, and T. Zhang, Stable adaptive neural network control. Boston, MA: Springer US, 2002. 


\section{BIOGRAPHIES OF AUTHORS}

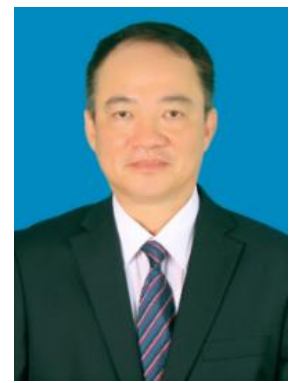

Nguyen Thai Duong (D) SC P received the B.S. and M.S. degree from Vietnam Maritime University, Haiphong, Vietnam, in 1990 and 1999, respectively, and the Ph.D. degrees from the Vietnam Maritime University, Hai Phong, Vietnam, in 2017. He is currently a lecturer of Faculty of Navigation, Vietnam Maritime University, Haiphong, Vietnam. His current research interests include positioning navigation science, maritime environmental science, linear and nonlinear systems, adaptive dynamic programming control, and model predictive control. During on board vessels also he was an experienced captain of ocean. He can be contacted at email: nguyenthaiduong@vimaru.edu.vn.

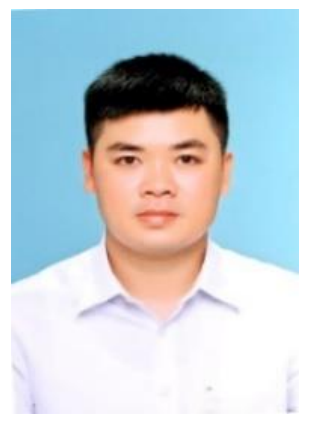

Nguyen Quang Duy (iD III SC P received the B.S. and M.S. degree from Vietnam Maritime University, Haiphong, Vietnam, in 2011 and 2014, respectively, and the Ph.D. degrees from the Dalian Maritime University, Dalian, Liaoning, China, in 2020. He is currently a lecturer of Faculty of Navigation, Vietnam Maritime University, Haiphong, Vietnam. His current research interests include linear and nonlinear systems, adaptive dynamic programming control, model predictive control, ship motion control, and sliding mode control. He can be contacted at email: nguyenquangduy@vimaru.edu.vn. 